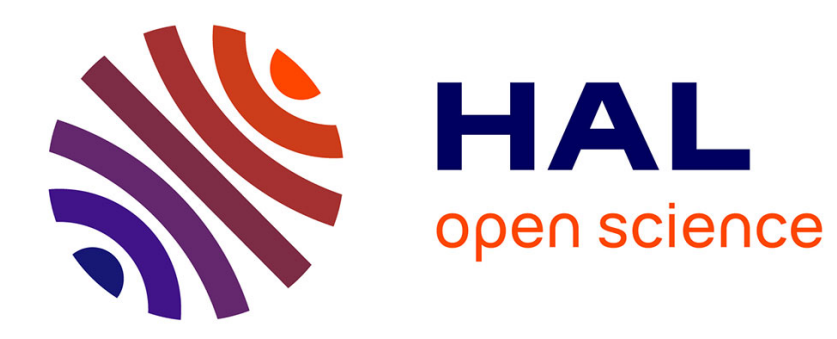

\title{
Radiative effects of tropospheric ionisation
}

K. L. Aplin

\section{To cite this version:}

K. L. Aplin. Radiative effects of tropospheric ionisation. Atmospheric Chemistry and Physics Discussions, 2003, 3 (3), pp.3205-3221. hal-00301106

\section{HAL Id: hal-00301106 https://hal.science/hal-00301106}

Submitted on 20 Jun 2003

HAL is a multi-disciplinary open access archive for the deposit and dissemination of scientific research documents, whether they are published or not. The documents may come from teaching and research institutions in France or abroad, or from public or private research centers.
L'archive ouverte pluridisciplinaire HAL, est destinée au dépôt et à la diffusion de documents scientifiques de niveau recherche, publiés ou non, émanant des établissements d'enseignement et de recherche français ou étrangers, des laboratoires publics ou privés. 
Atmos. Chem. Phys. Discuss., 3, 3205-3222, 2003

www.atmos-chem-phys.org/acpd/3/3205/

3, 3205-3222, 2003

Radiative effects of tropospheric ionisation

K. L. Aplin

\section{Radiative effects of tropospheric ionisation}

\section{K. L. Aplin}

Rutherford Appleton Laboratory, Space Science and Technology Department, Chilton, Didcot, Oxon OX11 OQX, UK

Received: 2 May 2003 - Accepted: 13 June 2003 - Published: 20 June 2003

Correspondence to: K. L. Aplin (k.l.aplin@ rl.ac.uk)

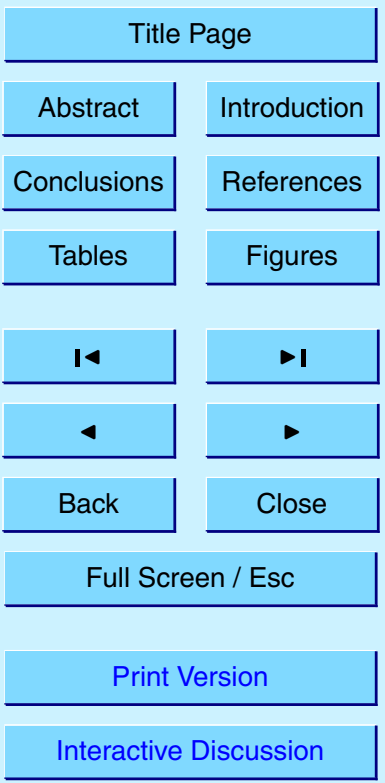

(c) EGU 2003 


\section{Abstract}

Despite the increasing evidence that cosmic ray variations may influence clouds and climate, there has been little discussion of the direct radiative effects of atmospheric ionisation. Laboratory experiments show that hydrated molecular cluster-ions, formed

5 in the atmosphere by cosmic rays, absorb in the infra-red continuum at wavelengths of $9-12 \mu \mathrm{m}$. The tropospheric magnitude of this effect is estimated: transmittance anomalies from clear sky ion concentrations peak at $2 \%$ at $10 \mathrm{~km}$ in the mid-latitudes. A simple isothermal clear sky atmospheric model suggests the integrated effect of the absorption is $\sim 2 \mathrm{Wm}^{-2}$. The effect appears detectable in existing surface data sets;

\section{Introduction}

Atmospheric aerosol electrification in non-thunderstorm conditions arises from hydrated cluster ions formed by radiolysis, primarily from cosmic rays. Possible connections between atmospheric electricity and climate have long been a source of speculation (e.g. Ney, 1959) but have a new urgency following establishment of the positive correlation between cosmic rays and satellite-derived cloud cover (Svensmark and Friis-Christensen, 1997). Quantifying the atmospheric radiative balance is fundamental to understanding natural and anthropogenic climate variability, and it is important to identify factors that may modulate it.

Several plausible physical mechanisms exist connecting ionisation to clouds and the planetary radiation balance (e.g. Yu and Turco, 2001; Harrison and Aplin, 2001; Tripathi and Harrison, 2002). These mechanisms are indirect and involve several (sometimes
ACPD

3, 3205-3222, 2003

Radiative effects of

tropospheric ionisation

K. L. Aplin

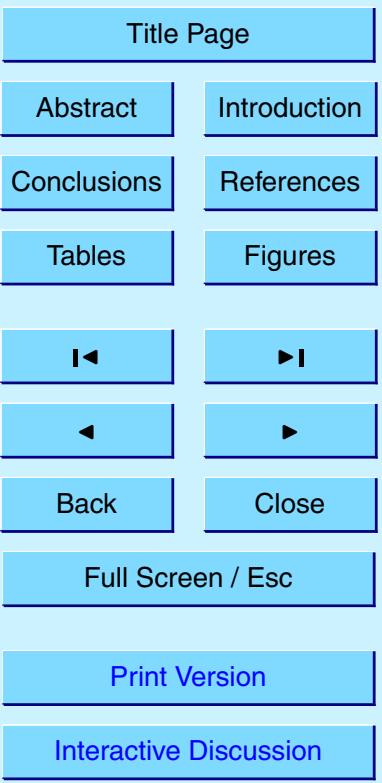

(C) EGU 2003 
highly contentious) steps. Investigation of the direct rôle of charged particles in radiative transfer processes has hitherto been very limited, yet there is increasing evidence that ionisation influences clouds and climate (Carslaw et al., 2002). Theoretical calculations show that the radiative absorption of charged water drops is negligible, but 5 sub-micron charged water clusters or droplets are more likely to absorb electromagnetic radiation (Geldart and Chylek, 2001). The simplicity of atmospheric cluster-ions directly absorbing solar radiation and modifying the radiative balance, summarised with the existing cloud mechanisms in Fig. 1, is a strong motivation. In this paper, the evidence for ion clusters directly absorbing infra-red radiation is discussed, and the 10 magnitude of the atmospheric effect estimated.

\section{The infra-red continuum problem}

The near infra-red (IR) atmospheric radiative properties of the water molecule are wellknown, and result from rotational and vibrational transitions of its hydrogen bonds (e.g. Peixoto and Oort, 1992). There also exists a weak broad-band (8-50 $\mu \mathrm{m})$ IR absorp15 tion, unattributed to any well-known atmospheric species, with pressure and temperature dependency greater than any known water vapour absorption. This anomaly between accepted theory and observations is referred to as the IR continuum problem. The possible presence of atmospheric water dimers is a long-established explanation (Bignell, 1970). Recent theoretical work implies that atmospheric water vapour clus20 ters, particularly dimers and trimers, do exist in sufficient concentrations to account for the continuum (Goldman et al., 2001; Evans and Vaida, 2000). However, oligomers of water have apparently never been measured in the atmosphere (Headrick and Vaida, 2001) and their molecular structure and associated radiative properties are poorly understood.

25 Continuum absorption effects are highly relevant for climate studies, as much of the present cloud climatology is based on IR satellite data. For example, the International Satellite Cloud Climatology Project (ISCCP) data set is a composite global satellite
ACPD

3, 3205-3222, 2003

Radiative effects of tropospheric ionisation

K. L. Aplin

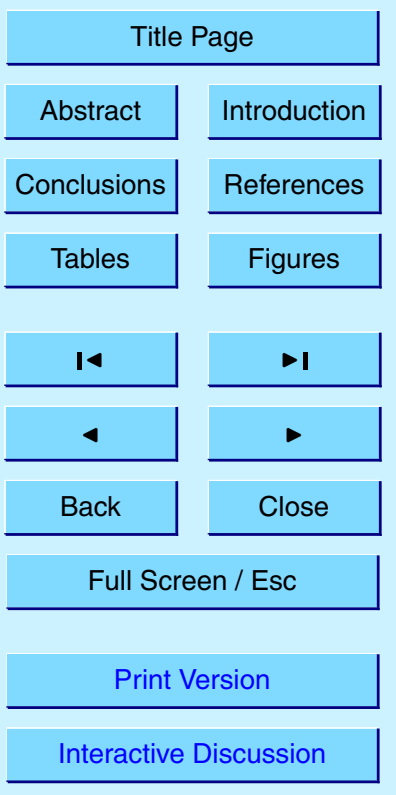

(C) EGU 2003 
cloud data set, frequently used in climate studies, derived from measurements in the IR and visible (Rossow, 1991). $60 \%$ of the satellites contributing IR measurements to the ISCCP data set measure in the IR continuum absorption range. A further motivation to understand the IR continuum is the need to quantify atmospheric water vapour 5 absorption and its variability, currently thought to be in the range $1-6 \mathrm{Wm}^{-2}$ (Chylek et al., 1999; Vaida et al., 2000). Radiative absorption of water vapour needs to be better understood to improve parameterizations for cloud models and calculate the water vapour contribution to greenhouse forcing (e.g. Brindley and Harries, 1998; Geldart and Chylek, 2001). The need for accurate climate change predictions clearly necessi10 tates investigation of any physical processes that may be relevant for the IR continuum problem.

\section{The role of molecular water clusters}

Atmospheric small ions are clusters of water molecules around a charged centre, typically represented by chemical formula $\mathrm{X}^{+}\left(\mathrm{H}_{2} \mathrm{O}\right)_{n}$ or $\mathrm{Y}^{-}\left(\mathrm{H}_{2} \mathrm{O}\right)_{n}$, where $n$ is the number 15 of water molecules in the cluster $(n<10)$ and $\mathrm{X}^{+}$and $\mathrm{Y}^{-}$are charged atmospheric species. Typical tropospheric ion concentrations are $10^{3}-10^{4} \mathrm{~cm}^{-3}$ (MacGorman and Rust, 1998). The charged water cluster $\mathrm{H}_{3} \mathrm{O}^{+}\left(\mathrm{H}_{2} \mathrm{O}\right)_{n}$ is a common tropospheric positive ion species (Keesee and Castleman, 1985; Nagato et al., 1999). Atmospheric small ions of different chemical composition are also hydrated to a similar extent and may

result in comparable radiative absorption properties to neutral water clusters such as dimers and trimers. Carlon and Harden (1980) and Carlon (1982a, b) found that the IR absorption properties of both neutral and charged molecular water clusters matched the pressure and temperature dependencies of the continuum absorption extremely well. This provoked their laboratory investigation of the IR absorption properties of charged water clusters, which is extended to the interactions of tropospheric ions and water vapour in this paper.

Carlon (1981a) showed that the positive molecular cluster ion species $\mathrm{H}_{3} \mathrm{O}^{+}\left(\mathrm{H}_{2} \mathrm{O}\right)_{n}$
ACPD

3, 3205-3222, 2003

Radiative effects of tropospheric ionisation

K. L. Aplin

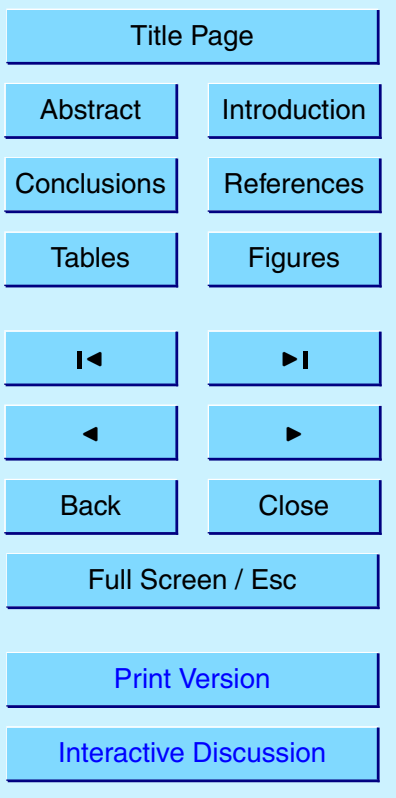

(c) EGU 2003 
can exist in equilibrium with larger neutral clusters. After perturbations to the chargedneutral cluster equilibrium, recovery takes place over a timescale of minutes to hours; the chemical changes during this return to equilibrium are thought to lead to the broadband IR absorption properties of the water vapour (Carlon, 1981b). Carlon found that 5 the positively charged cluster concentration is proportional to the calculated number of neutral clusters, and the IR absorption of water vapour varied as its positive ion concentration. Although the water cluster population is not known, (Headrick and Vaida, 2001) the positive ion concentration $N_{+}$can be measured via the positive air conductivity $\sigma_{+}$ by (1), where $\mu$ is the electrical mobility (e.g. Carlon, 1982b; Moore and Vonnegut, 10 1988)

$\sigma_{+} \approx N_{+} e \mu$.

In the closed, saturated system of Carlon's laboratory experiments, with ionisation enhanced by a radioactive source, the maximum concentration of charged water clusters was $\sim 10^{7} \mathrm{~cm}^{-3}$. Even these concentrations, which greatly exceed typical ion concentrations in the unsaturated free troposphere, are insufficient to explain the atmospheric IR continuum absorption. The interaction between charged and neutral clusters leads to the absorption signal of the charged clusters, but a larger concentration of neutral clusters is required to account for the atmospheric IR continuum absorption. Carlon (1981a) estimated neutral cluster concentrations in saturated air to be $10^{10}-10^{15} \mathrm{~cm}^{-3}$, 20 which is similar to the atmospheric dimer concentrations of $10^{10}-10^{14} \mathrm{~cm}^{-3}$ thought to be responsible for the IR continuum absorption (Vaida et al., 2000). A weak IR absorption from these neutral-charged cluster interactions may therefore occur in the cloud-free atmosphere, proportional to the positive molecular cluster-ion population.

\section{Atmospheric evidence for IR absorption of atmospheric ions}

25 IR radiation reaching the Earth is emitted from clouds and atmospheric molecular species. In the cloud-free sky, the longwave radiation reaching the surface is therefore
ACPD

3, 3205-3222, 2003

Radiative effects of tropospheric ionisation

K. L. Aplin

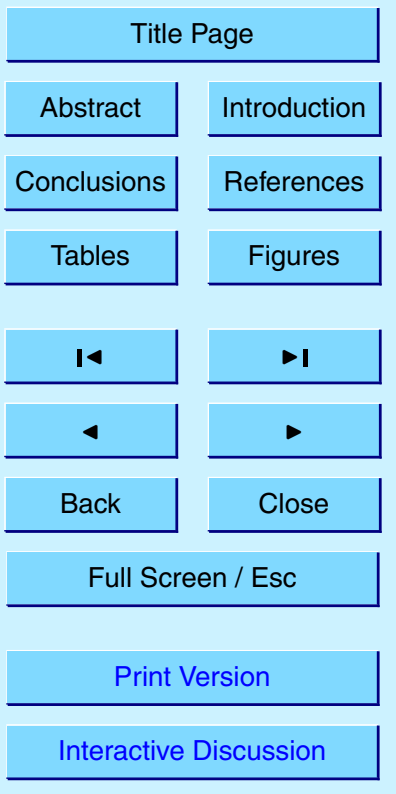

(c) EGU 2003 
determined by the integrated radiative properties of atmospheric species in the column of air above. If atmospheric ions do absorb significant quantities of IR radiation, this effect may be observable in the downwelling longwave radiation. The laboratory experiments discussed above show a greater ion concentration could lead to greater 5 absorption of IR, with an anticorrelation between the ion concentration and downwelling longwave radiation. Synchronous atmospheric ion and radiative flux measurements do not yet exist, but in the free troposphere, where aerosol concentrations are low, the ionisation rate is a good proxy for the ion concentration. Data from surface neutron counters is readily available to indicate the tropospheric ionisation rate from cosmic 10 rays $(\mathrm{CR})$. Low and high-energy $\mathrm{CR}$ can penetrate to the surface at high geomagnetic latitudes, but only high-energy $\mathrm{CR}$ are detected by neutron counters at equatorial latitudes (e.g. Wolfendale, 1963). In this section, measurements of the surface radiation balance are analysed and compared to neutron counter data as a proxy for ionisation.

Downwelling longwave radiation $L_{d}$ is one component of the net radiative flux density ${ }_{15} R_{n}$

$R_{n}=S_{g}+S_{d}+\left(L_{d}-L_{u}\right)$,

where $S_{g}$ is the global solar irradiance, $S_{d}$ the reflected irradiance, $L_{d}$ the downwards long-wave flux and $L_{u}$ the upwards long-wave flux. $R_{n}, S_{g}$ and $S_{d}$ are routinely measured. $L_{u}$ can be estimated for the earth's surface by assuming it is a black body radiating at a temperature $T_{a}$. Because of the limited spectral response of instruments used to measure $R_{n}$, only the fraction of the radiation in the wavelength window of the instrument is read. Using the Planck spectrum and the Stefan-Boltzmann law, (Houghton, 2002), $L_{d}$ can therefore be calculated from (3):

$$
L_{u}=\frac{\int_{\lambda_{1}}^{\lambda_{2}} \frac{8 \pi h c \lambda^{-5} d \lambda}{\exp \left\{h c /\left(k \lambda T_{a}\right)-1\right\}}}{\int_{0}^{\infty} \frac{8 \pi h c \lambda^{-5} d \lambda}{\exp \left\{h c /\left(k \lambda T_{a}\right)-1\right\}}} \sigma T_{a}^{4} .
$$

ACPD

3, 3205-3222, 2003

\section{Radiative effects of tropospheric ionisation}

K. L. Aplin

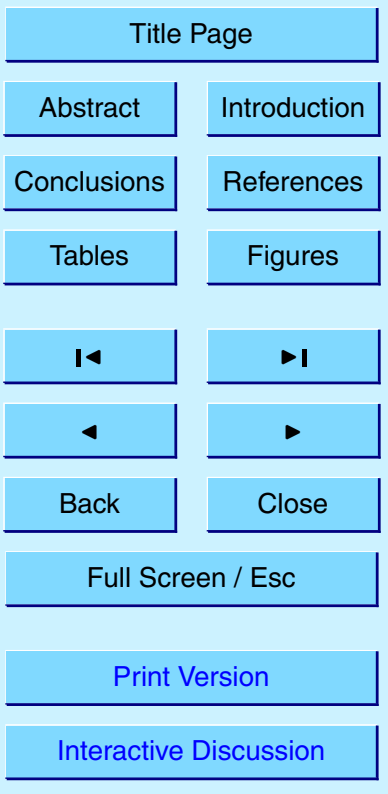

(c) EGU 2003 
(2) permits $L_{d}$ to be found as the residual, given values of $L_{u}, R_{n}, S_{g}$ and $S_{d}$.

The HAPEX-Sahel micrometerological experiment in 1992 measured $10 \mathrm{~min}$ average surface fluxes in the Sahel region of Africa, near Niamey, Niger $\left(13^{\circ} 30^{\prime} \mathrm{N}, 2^{\circ} 5^{\prime} \mathrm{E}\right)$ (Gash et al., 1997). This data set was chosen because it was a summer experiment with many 5 clear days, and the tropical latitude maximised flux values compared to the expected signal. $S_{g}$ and $S_{d}$ were measured to $\pm 3 \%$ using Kipp and Zonen CM5 solarimeters, and $R_{n}$ to $\pm 5 \%$ with a Middleton net radiometer. Emitted IR radiation in the 8-14 $\mu \mathrm{m}$ range was measured indirectly using a surface viewing Heimann KT15 IR thermometer $\left( \pm 0.1^{\circ} \mathrm{C}\right)$. This gives the radiative temperature of the surface, which can be used to 10 calculate the upwelling longwave radiation from (3) for $\lambda_{1}=8 \mu \mathrm{m}$ and $\lambda_{2}=14 \mu \mathrm{m}$. Coincident daily average values of neutron count rates were obtained from the University of Oulu/Sodankyla Geophysical Observatory, Finland $\left(67^{\circ} 22^{\prime} \mathrm{N}, 26^{\circ} 38^{\prime} \mathrm{E}\right)$. This highlatitude station covers a broader CR spectral range than is measured in the tropics; daily moving averages were calculated in order to extract the global daily CR fluctuations. Daily (144 point) centred moving averages of $L_{d}$ were also calculated; averages containing less than 130 data points because of instrument problems were excluded.

As cloud emits longwave radiation, cloud-free days provide the simplest conditions for a CR- $L_{d}$ comparison. Weather conditions at Niamey were generally fine with scattered cumulus clouds; there were 6 clear days over the measurement period, and 26 days out of 40 on which the integrated solar radiation exceeded $80 \%$ of the maximum possible for the time of year, here called "sunny days". Sunny periods were more persistent than totally clear days, and the daily averaged effects of scattered cumulus cloud are probably unlikely to contribute significantly to $L_{d}$ emission. The two periods of six consecutive sunny days when $L_{d}$ and CR data were available were selected for further analysis, using anomalies from a linear trend over the duration of the experiment. During a period of enhanced cosmic ionisation, year days 227-232 (14-19 August 1992), the correlation between the $L_{d}$ and neutron counter anomalies was -0.752 with $N=721$ pairs of measurements, Fig. 2. Persistence in the $L_{d}$ measurements reduced this to a statistical significance of $97.6 \%$.
ACPD

3, 3205-3222, 2003

Radiative effects of tropospheric ionisation

K. L. Aplin

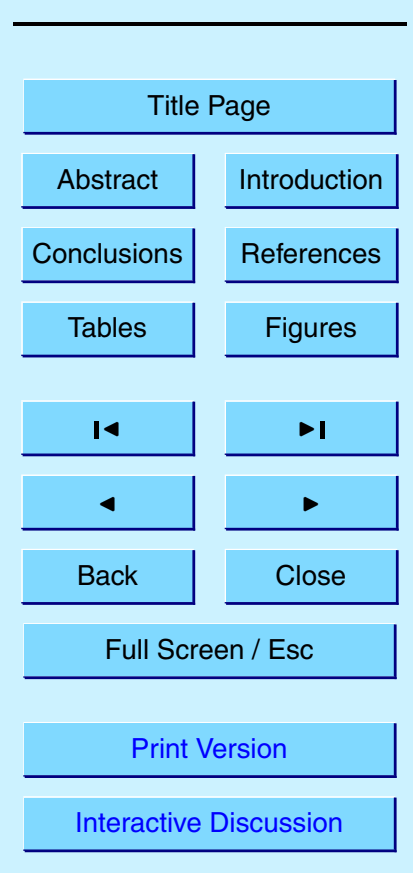

(c) EGU 2003 
The error in the calculated upwelling longwave radiation derived from the IR thermometer measurements was determined empirically as $\pm 2 \%$. Propagation of errors from the quantities measured in (2) gives the overall uncertainty in the derived $L_{d}$ as $\pm 7 \%$. Series of random errors within this range were generated and added to $L_{d}$; the 5 correlation with $\mathrm{CRs}$ remained statistically significant. The anticorrelation therefore persists even when conservative experimental error is considered. Correlations with other radiative quantities for the same period were also calculated for comparison, Table 1. The insignificance of these correlations indicates the physical mechanism causing the anticorrelation acts uniquely between $L_{d}$ and CRs. This supports the laboratory evidence that ion species present in the atmosphere absorb IR radiation.

\section{Estimation of tropospheric ion absorption profile}

The detailed mechanism of ions absorbing IR radiation as they interact with neutral clusters is clearly very complex. The magnitude of this effect throughout the troposphere is estimated below. Simplified representations of the positive ion concentration,

absorption cross-section and pressure variation with height are included. Water vapour absorption is excluded, and the positive ion composition is assumed to be entirely composed of water ion clusters $\mathrm{H}_{3} \mathrm{O}^{+}\left(\mathrm{H}_{2} \mathrm{O}\right)_{n}$.

Carlon (1982a) measured absorption cross-section $\alpha$ and $N_{+}$in the 8-13 $\mu \mathrm{m}$ band, and found a positive linear relationship between $\alpha$ and $N_{+}$outside the condensation 20 régime. The IR continuum wavelengths of 9.3 and $11.78 \mu \mathrm{m}$ are selected for further analysis here because the experimental ion concentrations were closest to those found in the troposphere. Linear regression is used to estimate $\alpha$ as a function of $N_{+}$; the linear correlation coefficient between $\alpha$ and $N_{+}$was 0.932 at $9.3 \mu \mathrm{m}$ and 0.711 at $11.78 \mu \mathrm{m}$. Although the absorption of water vapour, and other species, is almost negli-
ACPD

3, 3205-3222, 2003

Radiative effects of tropospheric ionisation

K. L. Aplin

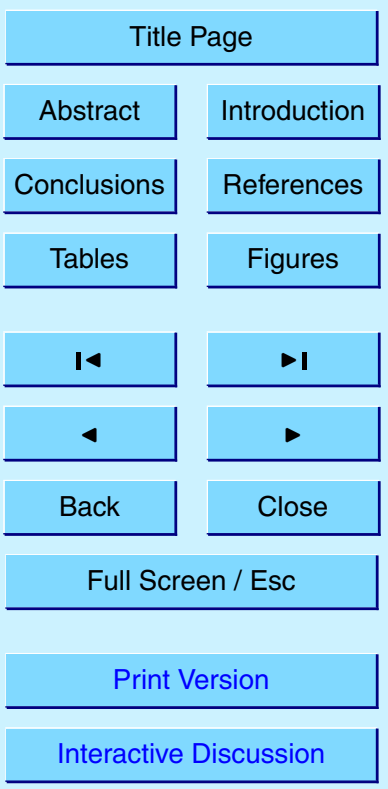

(c) EGU 2003 several weak vacuum absorption lines near these wavelengths in the HITRAN spectroscopic database (Rothman et al., 1998). The limitations of Carlon's experiments at 
atmospheric pressure and the vacuum lines in HITRAN prevent detailed comparisons, but there is evidence that water vapour absorption may be responsible for the slight positive offsets in the $\alpha-N_{+}$regression. The intensity of water vapour absorption in Carlon's experiment at $11.78 \mu \mathrm{m}$ can be calculated from the offset of $0.1909 \mathrm{gcm}^{-2}$ to 5 be $4.85 \times 10^{-21} \mathrm{~cm}^{2}$ molecule ${ }^{-1}$. The intensity of the vacuum absorption at $11.77 \mu \mathrm{m}$ is $2.11 \times 10^{-20} \mathrm{~cm}^{2}$ molecule ${ }^{-1}$, which is comparable. $\alpha$ can therefore be expressed (in $\mathrm{gcm}^{-2}$ ) as

$\alpha=a N_{+}+b$,

where $a$ is the dependency on ion concentration (of order $10^{-6}$ ) and $b$ is a constant off10 set resulting from weak background water vapour absorption. Exclusion of measured background water vapour absorption in order to estimate the effect solely from ions gives

$\alpha=a N_{+}$.

The atmospheric ion concentration varies with height $z$ because of the variation of penetration in CRs throughout the atmosphere. This accounts for the maximum ion concentration of about $6000 \mathrm{~cm}^{-3}$ at $15 \mathrm{~km}$. Vertical tropospheric positive ion concentration measurements are reported in MacGorman and Rust (1998); the profile is well-approximated by a quadratic in $z$.

The Beer-Lambert law for transmission of light of wavelength $\lambda$ through a medium of thickness $S$ is

$\frac{I}{I_{0}}(\lambda)=\exp [-\rho \alpha(\lambda) S]$

(e.g. Peixoto and Oort, 1992) where $I / I_{0}$ is the ratio of received to initial intensity (the transmittance), and $\rho$ is the density. Absorption by atmospheric ions varies with height $z$, as both $\rho$ and $\alpha$ are functions of $z$. The transmittance profile can therefore be

ACPD

3, 3205-3222, 2003

Radiative effects of tropospheric ionisation

K. L. Aplin

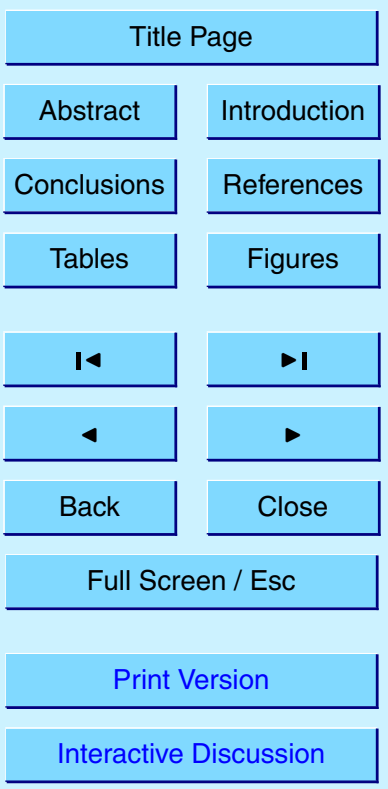

(C) EGU 2003 
by combining (5) and (6), and using a standard exponential atmosphere assumption for $\rho(z)$ (e.g. Seinfeld and Pandis, 1998). Calculations using (7) are presented in Fig. 3.

$5 \quad$ Estimated transmittance anomalies (Fig. 3) are negligible close to the ground, as expected from the relatively low atmospheric ion concentrations and short path length. The transmittance drops sharply as $N_{+}$increases and $\rho$ decreases, to a minimum at $\sim 10 \mathrm{~km}$ of $97.4 \%$ at $9.3 \mu \mathrm{m}$ and $98.6 \%$ at $11.78 \mu \mathrm{m}( \pm 0.5 \%)$. The minimum in transmittance at $\sim 10 \mathrm{~km}$ corresponds to a balance between the increasing ion concentration and decreasing atmospheric density, at comparable heights to high cloud. The increased penetration of CRs then causes the ionisation and cross section to rise less steeply up to $25 \mathrm{~km}$ where the anomaly is $\sim 0.5 \%$.

The radiative effect of integrated ion absorption can be estimated by assuming a simple cloud-free one-layer isothermal atmosphere, perfectly absorbing in the IR, and 15 perfectly transparent in the solar spectrum with albedo of 0.3 and atmospheric IR emissivity of 0.9 (e.g. Houghton, 2002). This gives a mean surface temperature $T_{s}$ of $296 \mathrm{~K}$, and an atmospheric temperature $T_{a}$ of $249 \mathrm{~K}$. The contribution of the 9-12 $\mu \mathrm{m}$ band to the total Planck black-body spectrum was calculated at $T_{a}$. If the integrated ionic absorption of ions is estimated to be $5 \%$ across the $9-12 \mu \mathrm{m}$ region, the radiative effect 20 at $T_{a}$ can then be estimated from the Stefan-Boltzmann law as $\sim 2 \mathrm{Wm}^{-2}$. Neglecting the radiative properties of hydrated cluster-ions could therefore represent an error of up to $0.5^{\circ} \mathrm{C}$ in temperatures derived from IR measurements.

\section{Discussion}

Carlon's laboratory experiments show strong evidence for the IR absorption proper-

Radiative effects of tropospheric ionisation

K. L. Aplin

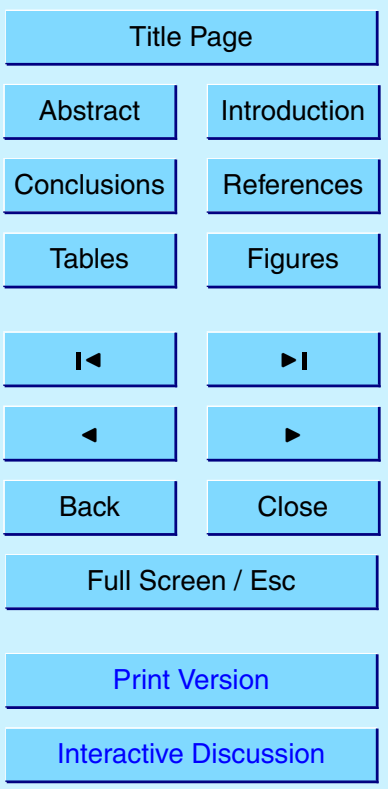

(C) EGU 2003 
atmospheric observations showing that downwelling IR fluxes in the 8-14 $\mu \mathrm{m}$ wavelength band in almost clear sky were significantly attenuated during a six-day period of increased CR ionisation. This has implications for satellite observations of meteorological parameters, such as cloud, retrieved from IR measurements. The well-known 5 correlation between cosmic rays and clouds (Svensmark and Friis-Christensen, 1997) appears to only exist in IR satellite data sets (Sun and Bradley, 2002; Kristjánsson et al., 2002). Its estimated magnitude is $1-2 \mathrm{Wm}^{-2}$, close to the predicted size of ionic absorption estimated above. These factors indicate that hydrated cluster-ions absorbing IR as they interact with neutral clusters could be an observable and significant 0 atmospheric effect.

This presents substantial evidence for the clear sky IR absorption properties of atmospheric ions. The predicted clear sky tropospheric IR absorption profile by protonated water cluster ions was estimated at $9.3 \mu \mathrm{m}$ and $11.78 \mu \mathrm{m}$, and transmittance was reduced by up to $(2.6 \pm 0.5) \%$. The sign of the observed effects is consistent with that expected from theory. Now that sufficiently sophisticated ion counters are available (Aplin and Harrison, 2001), further measurements of both ions and longwave radiation are desirable. Vertical soundings would be of value in testing the predictions above in more detail, but further IR spectroscopy measurements would be required to determine the detailed spectral response.

It is important to quantify the IR absorption of atmospheric ions. If the effect is detectable, there are implications for satellite observations of meteorological parameters retrieved from IR measurements. An unparameterised absorption process such as the IR response of water cluster ions could cause spurious signals in satellite data.

Acknowledgements. R. G. Harrison supplied the HAPEX-Sahel data, and assisted with some 25 of its processing.
ACPD

3, 3205-3222, 2003

Radiative effects of tropospheric ionisation

K. L. Aplin

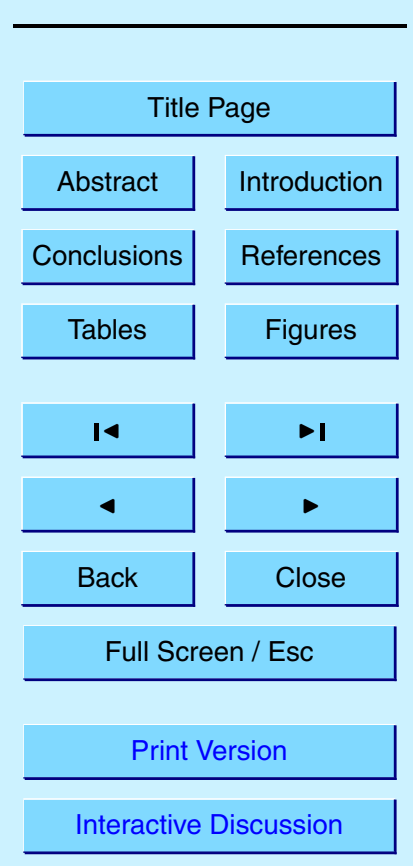

(C) EGU 2003 


\section{References}

Aplin, K. L. and Harrison, R. G.: A self-calibrating mobility spectrometer for atmospheric ion measurements, Rev. Sci. Inst., 72, 8, 3467-3469, 2001.

Bignell, K. J.: The water-vapour infra-red continuum, Q. J. Roy. Met. Soc., 96, 390-403, 1970.

5 Brindley, H. E. and Harries, J. E.: The impact of far ir absorption on clear sky greenhouse forcing: Sensitivity studies at high spectral resolution, J. Quant. Spectroscopy \& Radiative Transfer, 60, 2, 151-180, 1998.

Carlon, H. R. and Harden, C. S. Mass spectrometry of ion-induced water clusters: an explanation of the infrared continuum absorption, Applied Optics, 19, 11, 1776-1786, 1980.

Carlon, H. R.: Mass spectrometry of ion-induced water clusters: an explanation of the infrared continuum absorption - addendum, Applied Optics, 20, 5, 726-727, 1981a.

Carlon, H. R. Ionic equilibria and decay times of neutral water clusters in moist air, J. App. Phys., 52, 3, 1584-1586, 1981b.

Carlon, H. R. Infrared absorption and ion content of moist atmospheric air, Infrared Physics, $1522,43-49,1982 a$.

Carlon, H. R.: New measurements of the ion content of evaporation-humidified air, J. Chem. Phys., 76, 11, 5523-5529, 1982b.

Carslaw, K. S., Harrison, R. G., and Kirkby, J.: Cosmic rays, clouds, and climate, Science, 298 (5599), 1732-1737, 2002.

20 Cormier, J. G., Ciurylo, R., and Drummond, J. R.: Cavity ringdown spectroscopy measurements of the infrared water vapor continuum, J. Chem. Phys., 116, 3, 1030-1034, 2002.

Chylek, P., Fu, Q., Tso, H. C. W., and Geldard, D. J. W.: Contribution of water vapor dimers to clear sky absorption of solar radiation, Tellus A., 51, 2, 304-313, 1999.

Evans, G. T. and Vaida, V.: Aggregation of water molecules: Atmospheric implications, J. Chem. Phys., 113, 16, 6652-6659, 2000.

Gash, J. H. C., Kabat, P., Monteny, B. A., Amadou, M., Bessemoulin, P., Billing, H., de Bruin, H. A. R., Elbers, J. A., Friborg, T., Harrison, R. G., Holwill, C. J., Lloyd, C. R., Lhomme, J.-P., Moncrieff, J. B., Puech, D., Soegaard, H., Taupin, J. D., Tuzet, A., and Verhoef, A.: The variability of surface fluxes during the HAPEX-Sahel Intensive Observation Period, J. Hydrol. 188-189, 385-399, 1997.

Geldart, D. J.,W. and Chylek, P.: Absorption of solar radiation by charged water droplets, J. Quant. Spectroscopy and Radiative Transfer, 70, 697-708, 2001.
ACPD

3, 3205-3222, 2003

Radiative effects of

tropospheric

ionisation

K. L. Aplin

\section{Title Page}

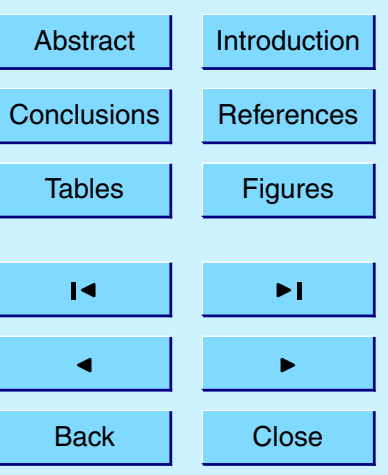

Full Screen / Esc

Print Version

Interactive Discussion

(C) EGU 2003 
Goldman, N., Fellers, R. W., Leforestier, C., and Saykally, R. S.: Water dimers in the atmosphere: equilibrium constant for water dimerization from the VRT(ASP-W) potential surface, J. Phys. Chem A., 105, 3, 515-519, 2001.

Harrison, R. G. and Aplin, K. L.: Atmospheric condensation nuclei formation and high-energy radiation, J. Atmos. Solar Terrestrial Physics, 63, 17, 1811-1819, 2001.

Headrick, J. E. and Vaida, V.: Significance of water complexes in the atmosphere, Phys. Chem. Earth, 26, 7, 479-486, 2001.

Houghton, J. T. The physics of atmospheres, 3nd edition, Cambridge University Press, Cambridge, 2002.

10 Keesee, R. G. and Castleman, A. W.: Ions and cluster ions, experimental studies and atmospheric observations, J. Geophys. Res, 90, 5885-5890, 1985.

Kristjánsson, J. E., Staple, A., Kristiansen, J., and Kaas, E.: A new look at possible connections between solar activity, clouds and climate, Geophys. Res. Lett., 29, 23, 2107, doi:10.1029/2002GL015646, 2002.

MacGorman, D. R. and Rust, W. D.: The electrical nature of storms, Oxford University Press, Oxford, 1998.

Moore, C. B. and Vonnegut, B.: Measurements of the electrical conductivities of air over hot water, J. Atmos. Sci., 45, 5, 885-890, 1988.

Nagato, K., Tanner, D. J., Friedli, H. R., and Eisele, F. L.: Field measurement of positive ion mobility and mass spectra at a Colorado site in winter, J. Geophys. Res., 104, D3, 34713482, 1999.

Ney, E. P.: Cosmic radiation and the weather, Nature, 183, 415-452, 1959.

Peixoto, J. P. and Oort, A. H.: Physics of climate, American Institute of Physics, New York, 1992.

Rothman, L. S., Rinsland, C. P., Goldman, A., Massie, S. T., Edwards, D. P., Flaud, J. M., Perrin, A., Camy-Peyret, C., Dana, V., Mandin, J. Y., Schroeder, J., McCann, A., Gamache, R. R., Wattson, R. B., Yoshino, K., Chance, K. V., Jucks, K. W., Brown, L. R., Nemtchinov, V., and Varanasi, P.: The HITRAN molecular spectroscopic database and HAWKS (HITRAN Atmospheric workstation): 1996 edition, J. Quantitative Spectroscopy \& Radiative Transfer, $30 \quad 60,665-710,1998$.

Rossow, W. B.: Use of operational satellite data for study of clouds and radiation in climate, Palaeogeogr. Palaeoclim. Palaeoecol., 90, 33-39, 1991.

Seinfeld, J. H. and Pandis, S.: Atmospheric chemistry and physics, Wiley, New York, 1998.

ACPD

3, 3205-3222, 2003

Radiative effects of tropospheric ionisation

K. L. Aplin

\section{Title Page}

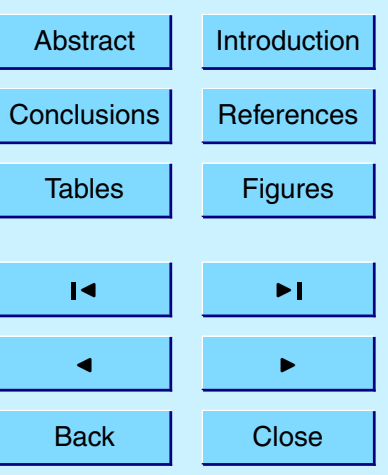

Full Screen / Esc

Print Version

Interactive Discussion

(C) EGU 2003 
Svensmark, H. and Friis-Christensen, E.: Variation of cosmic ray flux and global cloud coverage - a missing link in solar-climate relationships, J. Atm. Sol. Terr. Phys., 59, 1225-1232, 1997.

ACPD

Sun, B. and Bradley, R. S.: Solar influences on clouds and climate: A reassessment, J. Geophys. Res., 107, D14, doi:10.1029/2001JD000560, 2002.

5 Tripathi, S. N. and Harrison, R. G.: Enhancement of contact nucleation by scavenging of charged aerosol particles, Atmospheric Research, 62, 1-2, 57-70, 2002.

Vaida, V., Daniel, J. S., Kjaergaard, H. G., Goss, L. M., and Tuck, A. F.: Atmospheric absorption of near infrared and visible solar radiation by the hydrogen bonded water dimer, Q. J. Roy. Met. Soc., 127, 1627-1643, 2001.

10 Wolfendale, A.: Cosmic rays, Newnes, 1963.

Yu, F. and Turco, R. P.: From molecular clusters to nanoparticles: Role of ambient ionization in tropospheric aerosol formation, J. Geophys Res., 106, D5, 4797-4814, 2001.

\section{3, 3205-3222, 2003}

Radiative effects of tropospheric ionisation

K. L. Aplin

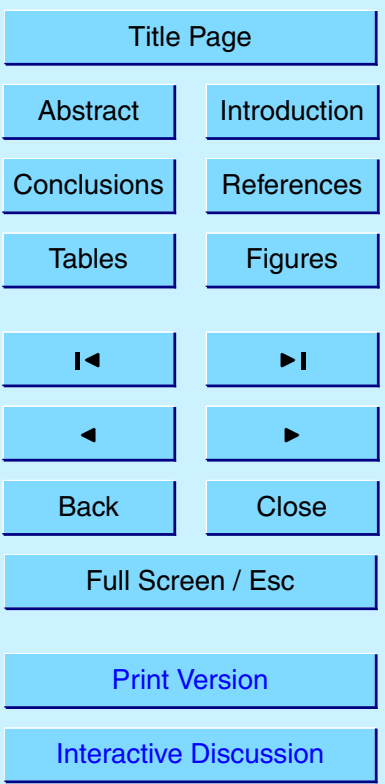

(C) EGU 2003 


\section{ACPD}

3, 3205-3222, 2003

Radiative effects of tropospheric ionisation

K. L. Aplin

Table 1. Correlations of daily averaged net radiation $R_{n}$, longwave up $L_{u}$ and longwave down $L_{d}$ in Niger with cosmic rays for days 227-232 1992

\begin{tabular}{ccc} 
Quantity & Correlation with cosmic rays for days 227-232 1992 & Statistical significance? \\
\hline$R_{n}$ & -0.117 & No \\
$L_{u}$ & -0.453 & No \\
$L_{d}$ & -0.752 & Yes \\
\hline
\end{tabular}

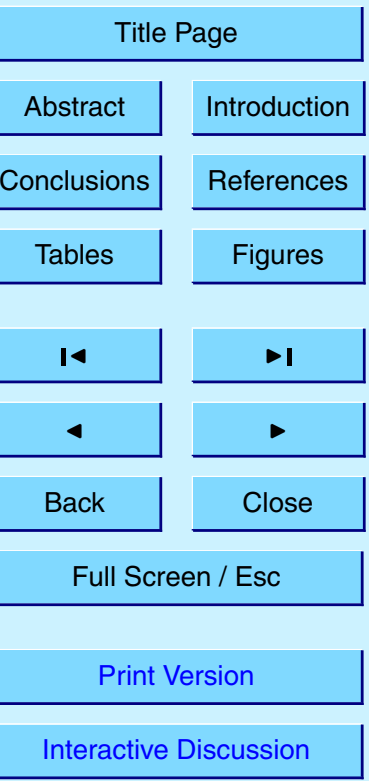

(c) EGU 2003 


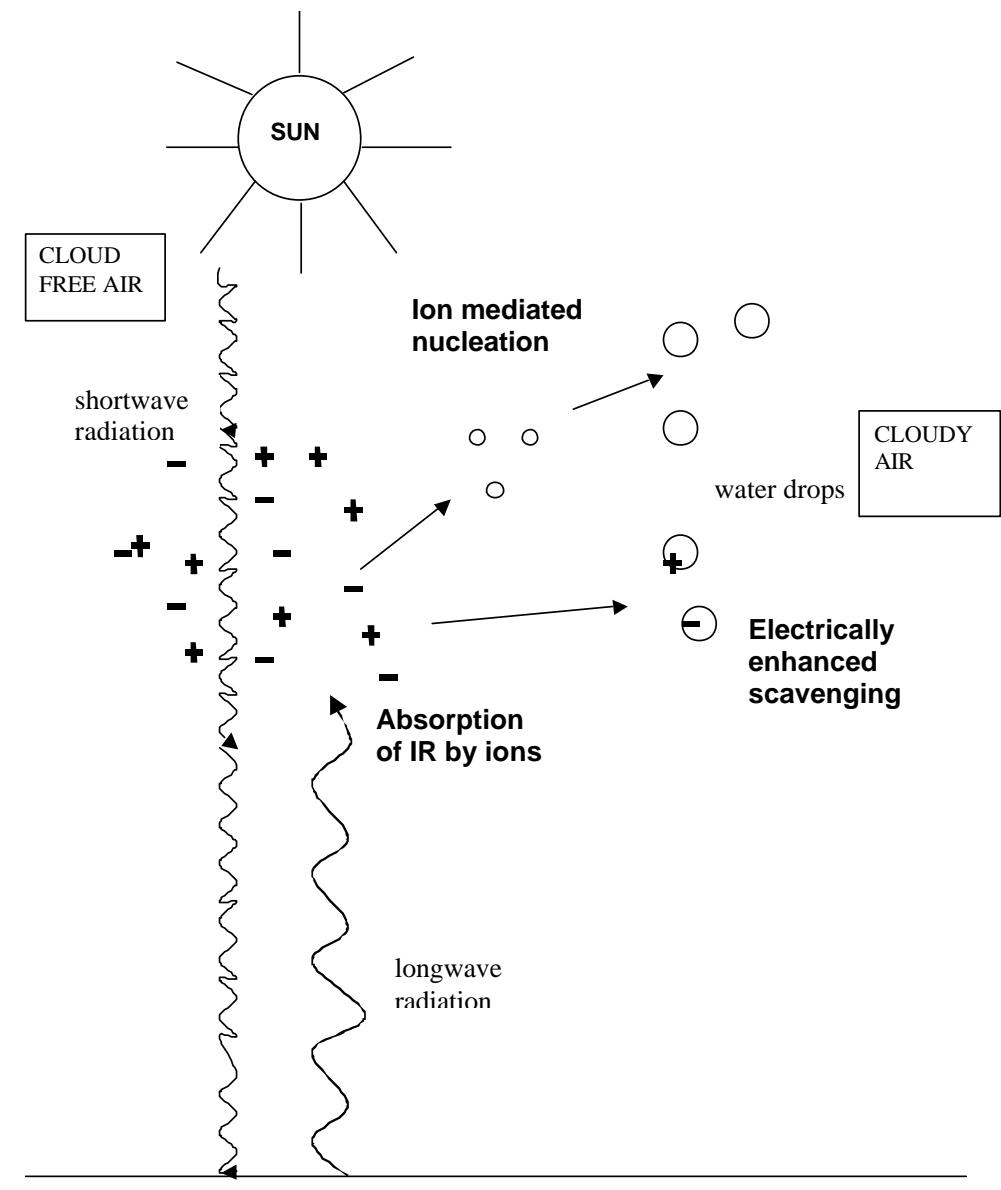

Fig. 1. Possible mechanisms by which ionisation in the atmosphere may influence the radiative balance.
ACPD

3, 3205-3222, 2003

Radiative effects of tropospheric ionisation

K. L. Aplin

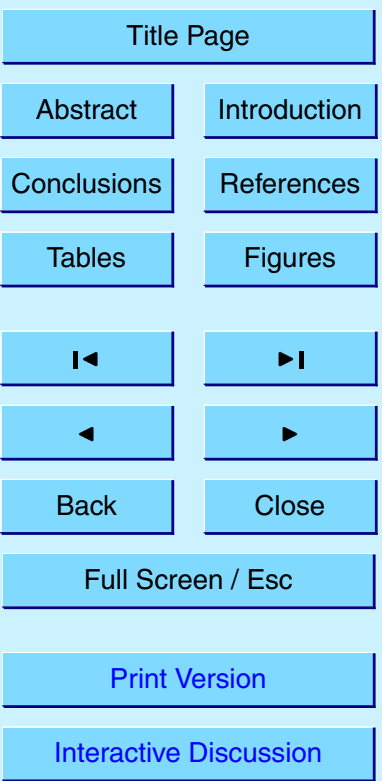

(C) EGU 2003 


\section{ACPD}

3, 3205-3222, 2003

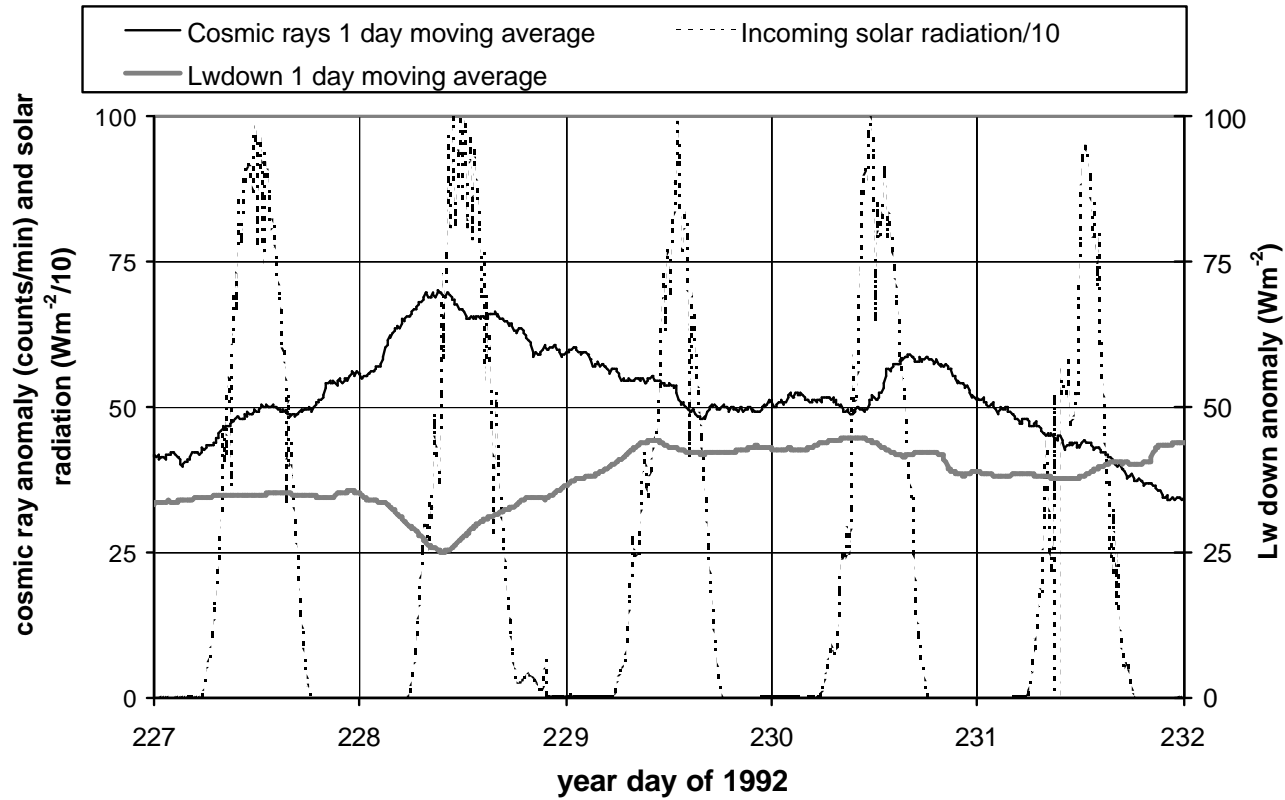

Radiative effects of tropospheric ionisation

K. L. Aplin

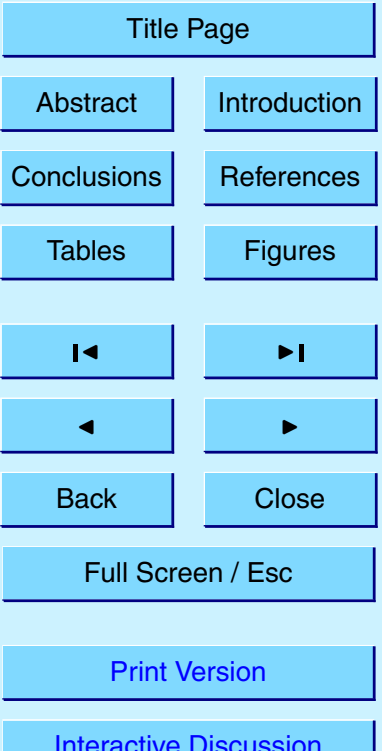

Interactive Discussion

(C) EGU 2003 


\section{Estimated clear sky transmittance profiles}

\section{ACPD}

3, 3205-3222, 2003

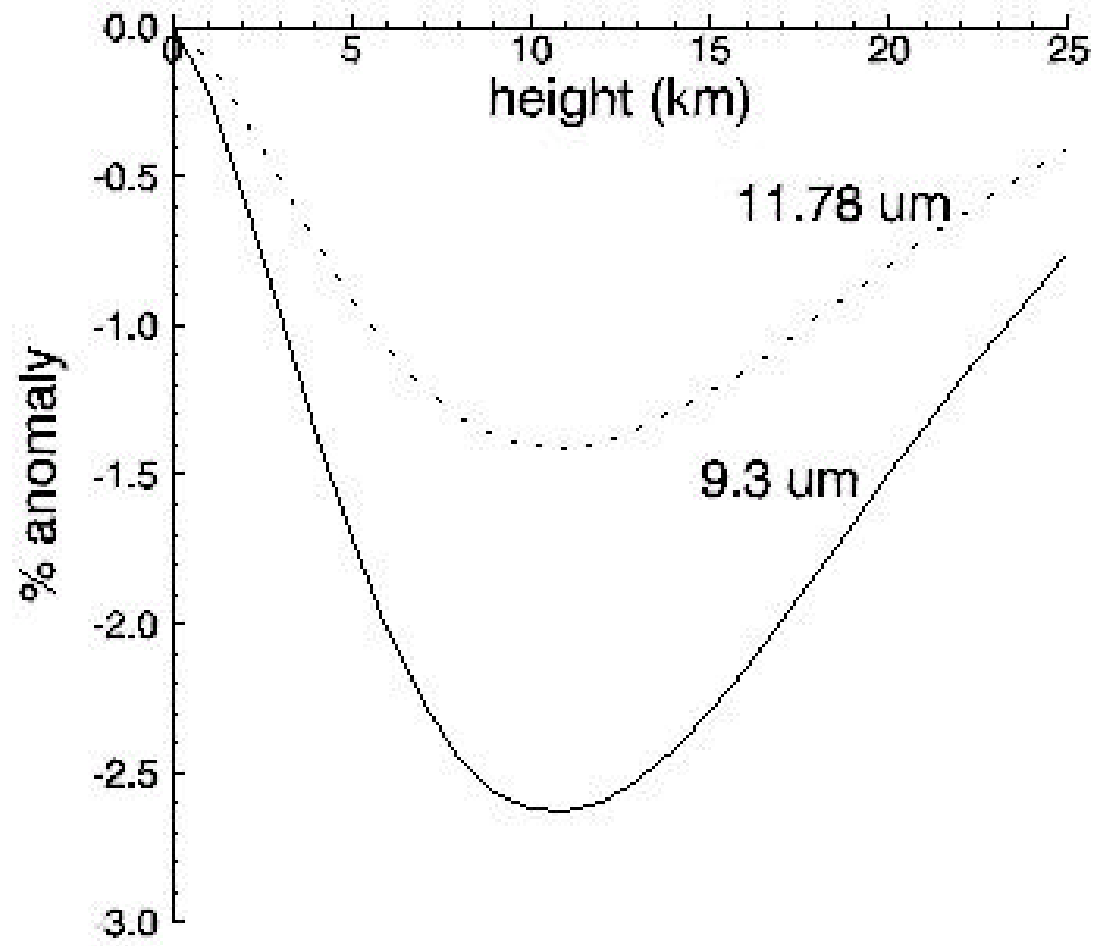

Radiative effects of tropospheric ionisation

K. L. Aplin

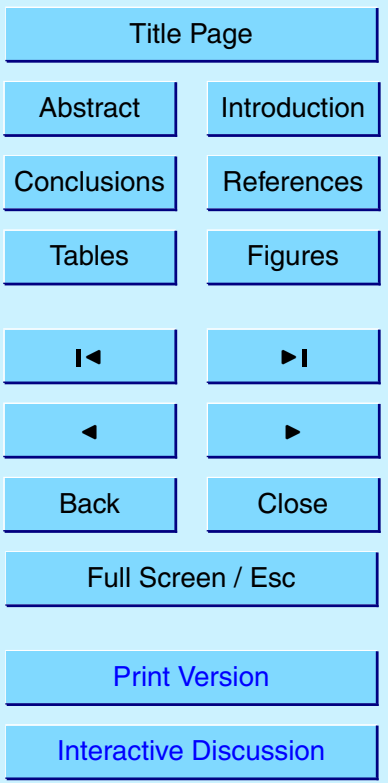

(C) EGU 2003 